\title{
TOTAL PHENOLIC CONTENTS AND ANTIOXIDANT ACTIVITY OF PALM OILS AND PALM KERNEL OILS AT VARIOUS REFINING PROCESSES
}

FADZLINA ABDULLAH*; ROSNAH ISMAIL*; RAZMAH GHAZALI* and ZAINAB IDRIS*

\begin{abstract}
Oil palm is one of the richest sources of antioxidants such as carotenoids, tocopherols, tocotrienols and phenolic compounds. This study quantified the amount of total phenolic content (TPC) and the antioxidant activity of crude to refined palm oil and palm kernel oil products obtained from palm oil mills. The TPC of the oil extracts was determined using Folin-Ciocalteau method expressed as gallic acid equivalent (GAE). Aqueous oil extraction with methanolic solvent was efficient and extract from crude palm oil (CPO) had the highest concentration of TPC. A reduction in trend was observed along the various stages of the refining steps probably due to losses through absorption of bleaching earth, volatilisation and degradation during the refining processes. The antioxidant activity was determined using 2,2-diphenyl-1-picrylhdrazyl (DPPH) assays. Results showed that the effect of antioxidants on DPPH radical scavenging activity decreases in the order of oil extracts $C P O>C P K O>R P O>R P K O>R P O o>P K O$. Overall, it was found that $C P O$ extract exhibited the highest antioxidant activity due to high TPC compared to other extracted oil samples.
\end{abstract}

Keywords: palm oil, palm kernel oil, total phenolic content, Folin-Ciocalteau colorimetric method, antioxidant activity, DPPH.

Date received: 21 July 2017; Sent for revision: 26 July 2017; Received in final form: 1 March 2018; Accepted: 22 October 2018.

\section{INTRODUCTION}

The oil palm (Elaeis guineensis), generally known as the most productive oil bearing crop, the source of two important edible oils, i.e. palm oil (PO) from the mesocarp and palm kernel and also produces high quality and versatile oils (Balasundram et al., 2005; Mukherjee and Mitra, 2009; Zou et al., 2012; Kushairi et al., 2017). In 2017, palm oil and palm kernel oil production recorded close to one-third (75.17 million tonnes) of world total oils and fats production from a planted area of 19.04 million hectares, mainly from Indonesia

Malaysian Palm Oil Board, 6 Persiaran Institusi,

Bandar Baru Bangi, 43000 Kajang,

Selangor, Malaysia.

E-mail: fadzlina@mpob.gov.my and Malaysia (Kushairi et al., 2018). PO and palm kernel oil are composed of fatty acids, esterified with glycerol just like any ordinary fat. Both are high in saturated fatty acids, about $50 \%$ and $80 \%$, respectively. The 16 carbon saturated fatty acid palmitic acid is the major fatty acid accounting for $44 \%$ of the total fatty acid composition found in PO followed by the monounsaturated oleic acid (39\%) while palm kernel oil contains a high level of lauric acid (Sambanthamurthi et al., 2000; Mukherjee and Mitra, 2009). Fractionation of crude palm oil (CPO) and crude palm kernel oil (CPKO) in the refinery produces the liquid fraction and a solid stearin component. Refined CPO denoted as refined, bleached and deodourised PO (RBDPO) has similar fatty acid composition to that CPO. Almost 90\% of the world PO productions are for edible uses. Identically, palm kernel oil is a popular feedstock 
for the formulation of cocoa butter substitutes (CBS) after fractionation and fully hydrogenation (De Clercq et al., 2012). A lot of studies on PO and its minor constituents have been conducted (Zou et al., 2012). This has created awareness on the nutritional properties of PO and its fractions. Like other fruits, the oil palm fruit is a rich source of water-soluble phenolic antioxidant (Neo et al., 2010). Palm fruits and $\mathrm{CPO}$ are known as rich sources of antioxidants such as carotenoids, tocopherols, tocotrienols and phenolic compounds (Szydłowska-Czerniak et al., 2011; Zou et al., 2012).

Phenolics are compounds possessing one or more aromatic rings with one or more hydroxyl group. They are broadly distributed in the plant kingdom and are the most abundant secondary metabolites of plants, ranging from simple molecules such as phenolic acids to highly polymerised substances such as tannins (Dai and Mumper, 2010). Compounds containing phenol moieties can act as free radical scavengers and there are anecdoted evidence showing that these compounds can prevent premature ageing and cancer caused by oxidative stress.

PO contains a number of minor components, including carotenoids, tocopherols, tocotrienols, sterols, phosphatides, triterpenic, aliphatic alcohols and phenolics compounds. Although these minor components account for less than $1 \%$ of the oil's constituents, they nevertheless play significant roles in maintaining the stability and quality of the oils (Abushita et al., 1997). In addition, some of these minor components, especially the phenolic compounds, carotenoids and vitamin E (tocopherols and tocotrienols), are important nutritionally. The protection that fruits and vegetables provide against several diseases has been attributed to the various antioxidants, vitamin $C$, vitamin $E$, $\alpha$-tocopherol, $\beta$-carotene and polyphenolic compounds (Abushita et al., 1997; Aruoma, 1998; Moure et al., 2001; Zou et al., 2012). Thus, PO is also a source of water-soluble phenolics antioxidant (Sambanthmurthi et al., 2000).

Solvent extraction was meant to recover and isolate the total water-soluble phenolics from the oil samples. This was carried out using a solvent to remove the phenolics from the oil. Polyphenolics are often most soluble in solvent less polar than water. Therefore, the efficiency of the extraction is determined by the proper selection of solvent, temperature and mechanical agitation to maximise polyphenolics recovery (Marinova and Yanishlieva, 1997). Phenolics with only a few hydroxyl groups are soluble in ether, chloroform, ethyl acetate, methanol and ethanol; phenolics with one or more aliphatic side chains require less polar solvents for their extraction (Harbone, 1989). By only reporting the soluble-free phenolics results in the underestimation of total phenolic content (TPC) and hydrolysis is usually required in order to release the bound phenolic compounds (Liyana-Pathirana and Shahidi, 2006).

Methanol, ethanol and acetone with different proportions of water have been used for the extraction of phenolic acids (Krygier et al., 1982). Aqueous methanol is a good choice of polar solvent because it is efficient, has a high boiling point, is economical (Kim and Lee, 2002) and has been successfully used in extracting polyphenolics from various vegetables and fruits (Hertog et al., 1992) such as apples (Oleszek et al., 1988), grapes (Lee and Jaworski, 1990), onions (Park and Lee, 1996), prunes and prune juice (Donovan et al., 1998), and banana bracts (Pazmino-Duran et al., 2001). Subsequent removal of the methanol was carried out under reduced pressure. The temperature for evaporation was $30^{\circ} \mathrm{C}-40^{\circ} \mathrm{C}$ (high power rotary evaporator). Solvent evaporation under reduced pressure and low temperatures minimises the degradation of extracted polyphenolics (Wrolstad et al., 2002). The reduction of phenolic compounds in oil samples may be accelerated by the lipid oxidation, high temperature heating and bleaching. In oilseed study, phenolic compounds are responsible for the dark colour, bitter taste and objectionable flavour of the resultant meal after oil extraction (Shahidi and Naczk, 1995).

The TPC is normally quantified based on the gallic acid calibration curve, and the result is expressed as $\mathrm{mg} \mathrm{kg}^{-1}$ gallic acid equivalent (GAE). Wrolstad et al. (2002) stated that gallic acid is preferred as the calibration standard because it is relatively pure and stable in its dry form. In addition, the response to gallic acid has been shown to be equivalent to most other phenolics in vegetables and fruits on a mass basis (Singleton et al., 1999). The Folin-Ciocalteau assay is often used to determine the total content of food phenolics (Brune et al., 1991; Deshpande and Cheryan, 1987; Earp et al., 1981; Hoff and Singleton, 1977). The determination of total phenolics using Folin-Ciocalteau colorimetric assay depends on the chosen calibration curve (e.g. caffeic acid, gallic acid, syringic acid, tyrosol, oleuropein equivalents) (Carrasco-Pancorbo et al., 2005).

Phenolics can act as radical scavengers or radical-chain breakers (Grassmann et al., 2002; Gil et al., 2000). The antioxidant properties of phenolics are mainly because of their potential redox properties, which allow them to act as reducing agents, hydrogen donors, and singlet oxygen quenchers (Rice-Evans et al., 1997). Phenolic acids also play an important role in combating oxidative stress in the human body by maintaining a balance between oxidants and antioxidants (Temple, 2000). According to Kaur and Kapoor (2001) antioxidants neutralise free radicals by donating one of their own electrons thereby ending the electron-stealing reaction. 
They act as scavengers and play the housekeeper's role by mopping up free radicals before they get a chance to act. Thus, antioxidants may well be defined as the substances that are capable of quenching or stabilising free radicals.

Radical scavenging is the main mechanism by which antioxidants act in food. The activity is assessed by the scavenging of synthetic radicals in polar organic solvent, e.g. methanol, at room temperature using 2,2-diphenyl-1-picrylhydrazyl $(\mathrm{DPPH}) . \mathrm{DPPH}$ is widely used to monitor the free radical scavenging abilities (the ability of a compound to donate an electron) of various antioxidants. The free radical scavenging activity of palm and palm kernel oils extracts has been studied by Brand-Williams et al. (1995). The study was based on the measurement of the reducing ability of antioxidants toward $\mathrm{DPPH}^{+}$, one of the few stable organic nitrogen radicals, which bears a deep purple colour due to its impaired electron, and the radical scavenging can be measured spectrophotometrically by the loss of absorbance at $517 \mathrm{~nm}$, as the pale yellow non-radical form was produced. Hence, the method has been widely used for rapid evaluation of the antioxidant activity of plant extracts relative to other methods. The phenolic compounds of palm products have great potential in the development of health-beneficial foods, feeds, cosmetic and pharmaceutical preparations (Pokorny et al., 2001).

The objective of this study is to determine the TPC of PO and palm kernel oils at different stages of refining processes. This article discusses the extraction process with methanolic solvent. The $\mathrm{DPPH}$ method was used for the determination of antioxidant activity of the oil samples. Moreover, TPC of the oil samples was analysed for possible correlation between the parameter with the antioxidant activity. The influence of the variation of the refining processes on the TPC and antioxidant activity of the PO and palm kernel oils was also evaluated.

\section{MATERIALS AND METHODS}

\section{Materials}

$\mathrm{CPO}$, refined palm oil (RPO), refined palm olein (RPOo), CPKO, refined palm kernel oil (RPKO), and refined palm kernel olein (RKOo) were commercial samples obtained from refineries, PO mills and kernel crushers from different regions in Malaysia (Table 1), while extra virgin olive oil (EVOO) was acquired from a local market, in Malaysia. All oil samples except EVOO were homogenised by melting in an oven set to $10^{\circ} \mathrm{C}$ above the melting point of the oils. EVOO was used as reference oil in this investigation.

\section{Chemicals}

Analytical grade solvents used include n-hexane, methanol, and ethanol; Galleon V2 Super bleaching earth, deionised water, distilled water, and granules of fused alumina from Ajax Finechem was used in laboratory-scale oil refining procedure. Phosphoric acid, salicylic acid and gallic acid with 95\% purity obtained from Sigma Chemical Co. (St Louis, MO, USA) were used for recovery study. Folin-Ciocalteau reagent was from Merck and anhydrous sodium carbonate purchased from Goodrich Chemical Enterprise was used for extraction of phenolics from palm and palm kernel oils. Gallic acid standard $(95 \%)$ and DPPH were purchased from Sigma Chemical Co. (St Louis, MO, USA), as control for DPPH assay. Milli-Q water $(18.2 \mathrm{M} \Omega \mathrm{cm})$ was used in all experiments. Filter paper was purchased from Whatman International Ltd (Maidstone, United Kingdom) and polytetrafluoroethylene (PTFE) filter membrane was used to purity the extracts.

\section{Methods}

Extraction of phenolics from palm and palm kernel oils. The phenolics were extracted from the oils according to the method proposed by Gutfinger (1981) and Koskiet al.(2003), with some modifications in the extracting solvent. Briefly, a $5 \mathrm{~g}$ sample of the homogenised oil was weighed accurately into a conical flask. The sample was dissolved in separating funnel with $5 \mathrm{ml}$ of $\mathrm{n}$-hexane in order to remove lipid fraction and was extracted three times, each time with $10 \mathrm{ml}$ of methanol:water $(80: 20, v / v)$. The pooled methanolic water extracts were then washed with $10 \mathrm{ml}$ of $\mathrm{n}$-hexane to remove residual oil. The combined aqueous methanolic extract was brought to dryness in a vacuum rotary evaporator set at $30^{\circ} \mathrm{C}$ $-40^{\circ} \mathrm{C}$. The residue containing the phenolic extract was then re-dissolved in $1 \mathrm{ml}$ of ethanol for analysis of phenolic content using the Folin-Ciocalteau assay. The experimental procedures were performed in triplicate and the data were expressed as means \pm standard deviation.

Some polyphenols are subjected to degradation during sample preparation and extraction due to light and oxidation. Purging with nitrogen gas during sample preparation prevented oxidation of polyphenolics. The samples were analysed within one day of extraction to prevent degradation.

Determination of total phenolic content (TPC) by the Folin-Ciocalteau method. After the aqueous methanol extraction, the amount of phenolic content from the oil samples was determined colorimetrically according to the Folin-Ciocalteau protocol by Gutfinger (1981) and Vazquez et al. (1973). Folin reagent is a mixture of tungsten and molybdenum oxides. In this assay, the reagent is reduced and the product of the metal oxide reduction has a blue colour that has a broad light 
absorption with a maximum at $765 \mathrm{~nm}$. The intensity of the light absorption follows the Beer Lambert Law, where absorption is proportional to the concentration of the phenolics.

Briefly, the Folin-Ciocalteau reagent was diluted with distilled water at 1:10 ratio and was used as stock solution. Then, $1 \mathrm{ml}$ of diluted Folin-Ciocalteau was added to $0.2 \mathrm{ml}$ of phenolic extract from the oil. This was followed by addition of $0.8 \mathrm{ml}$ of $7.5 \%$ sodium carbonate solution which was prepared earlier. After $30 \mathrm{~min}$, the phenolic extract was mixed well and the absorbance of blue coloured mixtures was read at $765 \mathrm{~nm}$ (Perkin Elmer LS 50B UV-Vis spectrophotometer). The TPC was calculated from a calibration curve of gallic acid standard solutions, and expressed as GAE per gram of the sample. The regression coefficient of calibration curve is $>0.99$. All measurements were done in triplicate and the results were expressed as means \pm standard deviation. While the analytical determination was being carried out, it is best that the prepared solution standard be kept under refrigeration until it is used. Standard solutions will retain $98 \%$ of their potency for two weeks if kept closed under refrigeration $\left(4^{\circ} \mathrm{C}\right)$, but this potency is retained for only five days at room temperature (Wrolstad et al., 2002).

Laboratory-scale oil refining process according to SCOPA process. The oils were (without phenolic extraction) then refined according to the method by the Seed Crushers' and Oil Processors Association (SCOPA) (Rice, 1980). The primary aim of this SCOPA test is to obtain samples of oil at different stages of the refining step as well as to obtain samples of palm fatty acid distillate (PFAD) for TPC analysis. The fatty acid which distilled from the oil during the deodorisation stage was collected in the condenser for TPC analysis. PFAD is a by-product of the physical refining of $\mathrm{PO}$.

\section{Recovery Study}

Quantitative extraction of phenolic compounds in natural matrices is difficult. Therefore, recovery studies were carried out to ensure the effectiveness of the extraction procedure of phenolic compounds from the oil. For recovery studies, a phenolicsfree oil sample (blank oil) was used and spiked with known levels of gallic acid. Recoveries were determined after analysis of TPC using the mean of three replicates and the data were expressed as means \pm standard deviation. The oil recovery for three replicate samples with gallic acid was expressed in terms of the percentage recovery and calculated as according to Equation (1):

$$
\text { Recovery }(\%)=\left(\mathrm{A}_{1} / \mathrm{A}_{0}\right) \times 100
$$

where: $\left(A_{0}\right)$ represents the concentration of gallic acid added in spiked sample, and $\left(A_{1}\right)$ is the mean concentration of three replicates samples that was gallic acid determined from TPC analysis. A calibration curve was also plotted using the gallic acid standards curve for spiking of the blank oil.

Removal of phenolics in palm kernel olein by column chromatography. For recovery studies, a phenolics-free oil sample was used for spiking with known levels of gallic acid. Phenolics in PKOo were removed by passing through a chromatography column. A glass column of $2 \mathrm{~cm}$ outer diameter was packed with n-hexane slurry of 1:1 (w/w) activated carbon black and diatomaceous earth to a height of $8 \mathrm{~cm}$. The column was then topped with a $1 \mathrm{~cm}$ layer of activated silicic acid. One hundred millilitres (100 $\mathrm{ml}$ ) of n-hexane containing $25 \mathrm{~g}$ of PKOo were then passed through the column. The oil was further eluted with $100 \mathrm{ml}$ of $\mathrm{n}$-hexane. The eluate was then collected and the n-hexane was evaporated off using a rotary evaporator, followed by flushing with nitrogen. The resulting oil, termed blank oil, was then confirmed to be phenolics-free by carrying out a TPC analysis using the Folin-Ciocalteau assay.

Determination of DPPH scavenging capacity. The potential antioxidant activity of the oil samples was assessed on the basis of the scavenging activity of the stable DPPH free radical, as previously described by Brand-Williams et al. (1995). A 0.1 mmol litre ${ }^{-1}$ solution of DPPH in methanol was prepared as stock solution. The radical stock solution was freshly prepared every day. Various concentration of $0.5 \mathrm{ml}$ phenolic extract of each sample solution was added to $3.5 \mathrm{ml}$ of DPPH radical solution. The mixture solution was then shaken vigorously and then allowed to stand at room temperature for $30 \mathrm{~min}$ in a dark room. The antioxidant activity was measured by decreased absorbance at $517 \mathrm{~nm}$ using a UVVis spectrophotometer until the reading reached a plateau. A low absorbance of the reaction mixture indicates a high free radical scavenging activity.

A blank solution consisted of $0.5 \mathrm{ml}$ of methanol and $3.5 \mathrm{ml}$ of DPPH radical solution. Standard $(0.5$ $\mathrm{ml}$ ) gallic acid solution at different concentrations was added to $3.5 \mathrm{ml}$ of $1 \mathrm{mg} \mathrm{ml}^{-1} \mathrm{DPPH}$ radical solution. These solutions were used as reference to determine the antioxidative potential of the phenolics extracts from the test oils.

The capability of EVOO, PO and palm kernel oil phenolic extracts to scavenge the DPPH radical was expressed as the inhibition percentage and was calculated using the Equation (2):

$$
\begin{aligned}
& \text { Radical-scavenging activity }(\%)=(\text { Control OD }- \\
& \text { Sample OD/Control OD) } \times 100
\end{aligned}
$$

where, Control OD was the optical density/ absorbance of the control (blank) reaction and Sample OD was the optical density/absorbance in the presence of the sample extracts. 
The $\mathrm{IC}_{50}$ (inhibitory concentration) value was determined from the plotted graph of scavenging activity versus the concentration of oils extracts, which is defined as the amount of antioxidant necessary to decrease the initial DPPH radical concentration by 50\%. Triplicate measurements were carried out and the antioxidant activity was calculated based on the percentage of DPPH scavenged and the data measurements were expressed as means \pm standard deviation.

Statistical analysis. The experimental results were performed in triplicate and the data were expressed as means \pm standard deviation. The statistical analysis was performed via MINITAB 13.0 software using analysis of variance (ANOVA) with the least significantly difference at the 0.05 probability level.

\section{RESULTS AND DISCUSSION}

\section{Recovery Study}

Quantitativeextraction of phenoliccompounds in oils was difficult. Therefore, recovery studies using spiked samples were carried out to determine the efficiency of the procedure used for extracting phenolic compounds from oils. The solvent used in this method was methanol:water $(80: 20, v / v)$. This system was chosen because methanol was less polar than water, and many organic compounds have a significantly higher solubility in methanol than in water. The ultimate goal is the preparation of an extract uniformly enriched in all compounds of interest and free from interfering matrix components (Tura and Robards, 2002). The recoveries for three replicates with gallic acid ranging from $2.0 \mathrm{mg} \mathrm{kg}^{-1}-30.0$ $\mathrm{mg} \mathrm{kg}^{-1}$ are shown in Table 1 . The results showed that the percentage mean recoveries ranged from 95.5\% - 99.5\%, which shows that the method of extraction used for extracting phenolics from the oil samples was satisfactory.

\section{Total Phenolic Content}

Table 2 shows the TPC in commercial PO samples from different $\mathrm{PO}$ mills and refineries. Results showed that the extract of $\mathrm{CPO}$ was found to have the greatest amount $\left(31.20 \mathrm{mg} \mathrm{kg}^{-1}-70.18 \mathrm{mg} \mathrm{kg}^{-1}\right)$ of phenolics, compared to refined palm products and the amounts of phenolics in the oils are in the order; $\mathrm{EVOO}>\mathrm{CPO}>\mathrm{CPKO}>\mathrm{RPO}>\mathrm{RPOo}>\mathrm{PKO}>$ RPKO. There were significant differences in TPC between all samples. EVOO was used as reference oil in this investigation as it is known to contain phenolic compounds and hydrophilic phenols (Boskou, 1996; Hafidi et al., 2005).

On the other hand, Tan and Howe (2005), studied the hydrophilic phenolic compounds in $\mathrm{CPO}, \mathrm{RBDPO}$ and neutralised bleached deodourised PO (NBDPO). TPC of CPO ranged from 40-70 mg $\mathrm{kg}^{-1}$ GAE, 5-17 mg kg-1 GAE in RBDPO and $1 \mathrm{mg}$ $\mathrm{kg}^{-1}$ GAE in NBDPO respectively. For comparison purpose, EVOO, was also analysed and found to contain $70.9 \mathrm{mg} \mathrm{kg}^{-1}$ of TPC. Besides TPC, the refining process also removes free fatty acids, phosphatides, odouriferous matter, water, as well as impurities such as dirt and traces of metals from the CPO. Phenolic compounds, which are present in significant amounts in virgin olive oil, are almost completely destroyed during the refining process of the oils (Nergiz and Unal, 1991). Carotenoids and phenolic compounds are removed almost totally, while vitamin E-active compounds and phytosterols are reduced by about $10 \%$ to $40 \%$ (Matthaus and Spener, 2008). According to Carrasco-Pancorbo et al. (2005), polyphenols are significantly related to the quality of virgin olive oil and their contribution to the oxidative stability of the oil is widely accepted. This indicated that the values obtained by the colorimetric assay can provide direct information on the amount of antioxidant phenolic groups in olive oil extracts. They are consequently related to the oxidative stability of virgin olive oil (Blekas et al., 2002). It is also strongly affected by the agronomic and technological conditions of its production.

TABLE 1. RECOVERY OF GALIC ACID STANDARD SPIKED IN PALM KERNEL OLEIN (PKOo)

\begin{tabular}{cccc}
\hline Sample $(\mathbf{n})$ & Gallic acid added $\left(\mathrm{mg} \mathrm{kg}^{-1}\right)$ & Gallic acid determined $\left(\mathbf{m g ~ k g}^{-1}\right)$ & $\%$ Average recovery \\
\hline 1 & 2.00 & $1.19 \pm 0.05$ & 95.5 \\
2 & 2.50 & $2.30 \pm 0.25$ & 92.2 \\
3 & 3.00 & $2.93 \pm 0.12$ & 97.7 \\
4 & 3.50 & $3.25 \pm 0.15$ & 95.5 \\
5 & 5.00 & $4.91 \pm 0.08$ & 98.2 \\
6 & 10.0 & $9.85 \pm 0.15$ & 98.5 \\
7 & 15.0 & $14.50 \pm 0.35$ & 92.3 \\
8 & 20.0 & $19.90 \pm 0.02$ & 99.3 \\
10 & 25.0 & $24.83 \pm 0.35$ & 99.3 \\
\hline
\end{tabular}

Note: Each value percentage recovery is expressed as the mean \pm standard deviation (S.D.) of triplicate analyses. 
TABLE 2. TOTAL PHENOLIC CONTENT (TPC) OF CRUDE PALM OIL (CPO), CRUDE PALM KERNEL OIL (CPKO), DIFFERENT PALM OIL (PO) AND PALM KERNEL OIL (PKO) FRACTIONS, AND EXTRA VIRGIN OLIVE OIL (EVOO)

\begin{tabular}{|c|c|c|c|}
\hline Sample No. & Oil & TPC $\left(\mathrm{mg} \mathrm{kg}^{-1} \mathrm{GAE}\right)^{*}$ & Sources \\
\hline 1 & $\mathrm{CPO}$ & $31.20 \pm 0.35$ & A \\
\hline 2 & $\mathrm{CPO}$ & $31.73 \pm 0.40$ & B \\
\hline 3 & $\mathrm{CPO}$ & $33.41 \pm 0.24$ & $\mathrm{C}$ \\
\hline 4 & $\mathrm{CPO}$ & $39.96 \pm 0.32$ & $\mathrm{D}$ \\
\hline 5 & $\mathrm{CPO}$ & $65.07 \pm 0.15$ & $\mathrm{E}$ \\
\hline 6 & $\mathrm{CPO}$ & $70.18 \pm 0.33$ & $\mathrm{~F}$ \\
\hline 7 & $\mathrm{BPO}$ & $18.36 \pm 0.35$ & A \\
\hline 8 & $\mathrm{BPO}$ & $18.59 \pm 0.27$ & B \\
\hline 9 & $\mathrm{BPO}$ & $21.47 \pm 0.30$ & $\mathrm{C}$ \\
\hline 10 & $\mathrm{BPO}$ & $21.59 \pm 0.10$ & $\mathrm{D}$ \\
\hline 11 & $\mathrm{BPO}$ & $22.05 \pm 0.15$ & $\mathrm{E}$ \\
\hline 12 & $\mathrm{BPO}$ & $22.25 \pm 0.15$ & $\mathrm{~F}$ \\
\hline 13 & $\mathrm{RPO}$ & $16.90 \pm 0.74$ & A \\
\hline 14 & $\mathrm{RPO}$ & $18.17 \pm 0.50$ & $\mathrm{~B}$ \\
\hline 15 & $\mathrm{RPO}$ & $21.24 \pm 0.46$ & $\mathrm{C}$ \\
\hline 16 & $\mathrm{RPO}$ & $25.12 \pm 0.33$ & $\mathrm{D}$ \\
\hline 17 & $\mathrm{RPO}$ & $25.91 \pm 0.24$ & $\mathrm{E}$ \\
\hline 18 & $\mathrm{RPO}$ & $26.89 \pm 0.32$ & $\mathrm{~F}$ \\
\hline 19 & RPOo & $11.36 \pm 0.60$ & A \\
\hline 20 & RPOo & $11.58 \pm 0.47$ & $\mathrm{~B}$ \\
\hline 21 & RPOo & $11.68 \pm 0.80$ & $\mathrm{C}$ \\
\hline 22 & RPOo & $11.95 \pm 0.31$ & $\mathrm{D}$ \\
\hline 23 & RPOo & $12.07 \pm 0.44$ & $\mathrm{E}$ \\
\hline 24 & RPOo & $12.20 \pm 0.40$ & F \\
\hline 25 & СРКО & $16.80 \pm 0.44$ & a \\
\hline 26 & СРКО & $17.64 \pm 0.30$ & $\mathrm{~b}$ \\
\hline 27 & СРКО & $17.97 \pm 0.22$ & c \\
\hline 28 & СРКО & $17.58 \pm 0.34$ & d \\
\hline 29 & СРКО & $27.05 \pm 0.21$ & $\mathrm{e}$ \\
\hline 30 & СРКО & $27.25 \pm 0.35$ & $\mathrm{f}$ \\
\hline 31 & RPKO & $3.159 \pm 0.30$ & a \\
\hline 32 & RPKO & $3.205 \pm 0.17$ & b \\
\hline 33 & RPKO & $3.720 \pm 0.20$ & c \\
\hline 34 & RPKO & $3.744 \pm 0.35$ & d \\
\hline 35 & RPKO & $3.802 \pm 0.30$ & e \\
\hline 36 & RPKO & $3.815 \pm 0.20$ & $\mathrm{f}$ \\
\hline 37 & PKOo & $2.521 \pm 0.20$ & $\mathrm{a}$ \\
\hline 38 & PKOo & $2.535 \pm 0.35$ & $\mathrm{~b}$ \\
\hline 39 & PKOo & $2.697 \pm 0.40$ & c \\
\hline 40 & PKOo & $8.058 \pm 0.30$ & $\mathrm{~d}$ \\
\hline 41 & PKOo & $8.185 \pm 0.15$ & e \\
\hline 42 & PKOо & $8.600 \pm 0.25$ & $\mathrm{f}$ \\
\hline 43 & EVOO & $65.07 \pm 0.45$ & A1 \\
\hline 44 & EVOO & $68.83 \pm 0.50$ & B2 \\
\hline 45 & EVOO & $70.21 \pm 0.30$ & $\mathrm{C} 3$ \\
\hline 46 & EVOO & $70.85 \pm 0.15$ & $\mathrm{D} 4$ \\
\hline 47 & EVOO & $71.06 \pm 0.25$ & E5 \\
\hline 48 & EVOO & $73.32 \pm 0.30$ & F6 \\
\hline
\end{tabular}

Note: *Values followed by upper case letters (A - F) from different palm oil refineries. While mean values with lower case letters (a - f) from different palm oil mills.

All results presented as mean values \pm standard deviation (S.D.) of triplicate analyses.

Values were based on regression analysis $\left(\mathrm{r}^{2}=0.9991\right)$ expressed as $\mathrm{mg} \mathrm{kg}^{-1}$ gallic acid equivalent $(\mathrm{GAE})$. BPO - bleached palm oil. PKOo - palm kernel olein. 
As most phenolics are water-soluble, they are probably removed during the refining process where live steam is used for stripping of free fatty acids from the oil during the de-acidification and deodorisation process. This accounted for the lower TPC in refined oils compared to crude oils. Phenolics are also being carried over into the fatty acid distillate during the deodorisation step (Scrimgeour, 2005).

After the first step of SCOPA process, the degummed and bleached oil (BPO) contained a lower amount of TPC compared to the CPO (4.4\% $6.4 \%$ ) reduction of TPC due to the oil is subjected to SCOPA bleach. This is attributed to the adsorption of some phenolics by the earth used and to remove colouring matters as well as to absorb any metal ions by the bleaching earth during the bleaching stage. In the final refined product, the RPO, the TPC has been reduced considerably, $(9.57 \%$ $14.02 \%)$. After going through the refining process, the oils still contain phenolic compounds but in a small amount of TPC.

Analysis of the PFAD samples obtained after the SCOPA process of CPO samples showed that a portion of the phenolics end up in the PFAD fraction. According to Scrimgeour (2005), phenolics are also being carried over into the fatty acid distillate during the deodourisation step. The TPC content was reduced by $9.2 \%-11.34 \%$ after the refining process of $\mathrm{CPO}$. The experiment showed that the refining process can remove phenolics and most probably the phenolics are volatilised. The phenolics were also carried over into the fatty acid distillate during the deodourisation step. Thus, in refined, bleached and deodourised palm oils, the content of TPC was reduced. The decrease in TPC with various stages of refining was also reported for rapeseed oil, silkworm pupa oil and kenaf seed oil (Szydłowska-Czerniak et al., 2015; Liu et al., 2016; Chew et al., 2016).

\section{DPPH Scavenging Capacity}

The DPPH scavenging activities of different oils are shown in Figure 1. There were significant differences in DPPH scavenging activities among all samples. EVOO was used as reference oil in this investigation and it showed the highest inhibition (70\% inhibition). The CPO extract exhibited significantly higher DPPH scavenging activity (45\% inhibition) followed by CPKO (30\% inhibition), RPO (29\% inhibition), RPOo (20\% inhibition), RPKO (15\% inhibition), PKOo (8\% inhibition). The results are indicative of the hydrogen donating ability of $\mathrm{CPO}$ phenol extract, since the effects of antioxidants on DPPH radical scavenging is thought to be due to their hydrogen donating ability (Grassmann et al., 2002).

Figure 2 shows the $\mathrm{IC}_{50}$ of different oil DPPH scavenging capacity of all the phenolic extracts from the test. The $\mathrm{IC}_{50}$ value was determined from the plotted graph of scavenging activity versus the concentration of oils extracts, which is defined as the amount of antioxidant necessary to decrease the initial DPPH radical concentration by $50 \%$. It is noted that a $20 \mathrm{mg} \mathrm{ml}^{-1}$ gallic acid standard solution exhibits $90 \%$ with the value $\mathrm{IC}_{50} 13.47 \mathrm{ml}$ $\mathrm{m}^{-1}$. Followed by CPO extract capacity exhibited significantly DPPH scavenging activity (13.39 $\left.\mathrm{mg} \mathrm{ml}^{-1}\right), \operatorname{EVOO}\left(13.50 \mathrm{mg} \mathrm{ml}^{-1}\right)$, RPO (13.23 mg $\mathrm{ml}^{-1}$ ), RPOo (12.05 $\mathrm{mg} \mathrm{ml}^{-1}$ ), and CPKO (12.88 $\mathrm{mg} \mathrm{ml} \mathrm{m}^{-1}$. RPKO and PKOo present at very low concentrations, so their definitive quantification was not attempted.

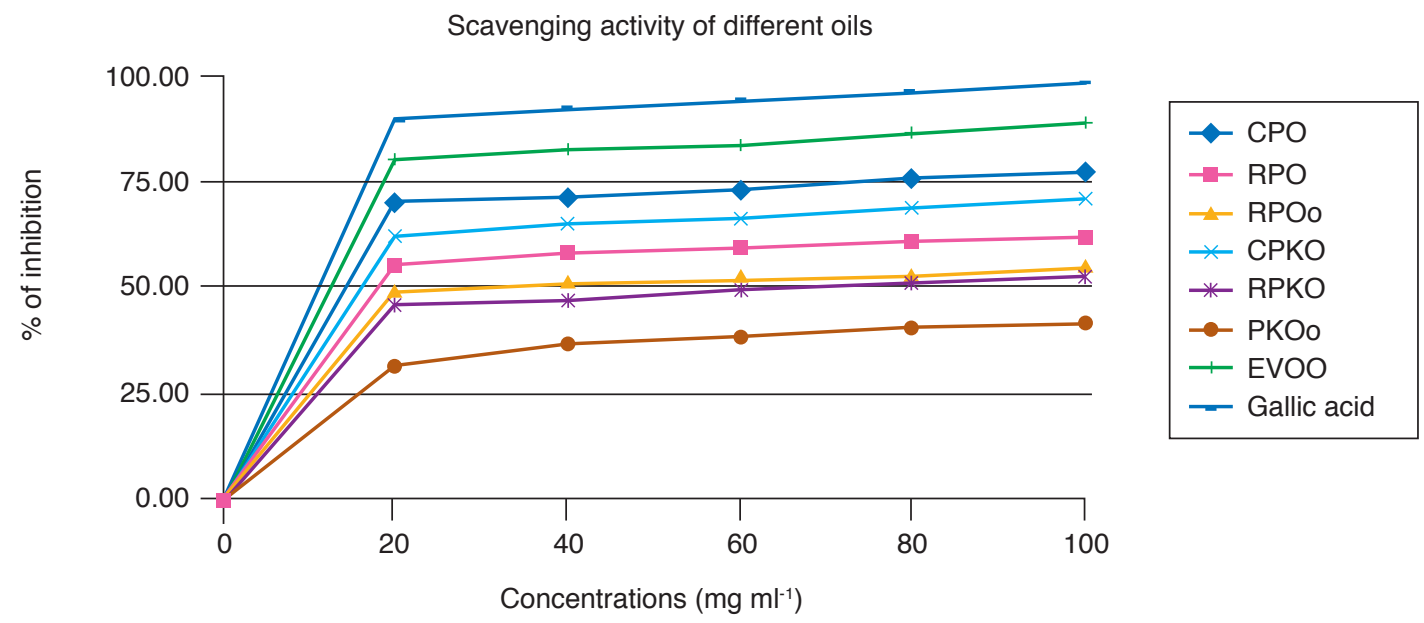

Note: CPO - crude palm oil. RPO - refined palm oil. RPOo - refined palm olein. RPKOo - refined palm kernel olein. CPKO - crude palm kernel oil. PKOo - palm kernel oil.

Figure 1. The 2,2-diphenyl-1 - picrylhydrazyl (DPPH) radical scavenging activity of extra virgin olive oil (CEVOO), palm and palm kernel oils extract. Each value is expressed as the mean \pm standard error (S.E.) of triplicate analyses. 


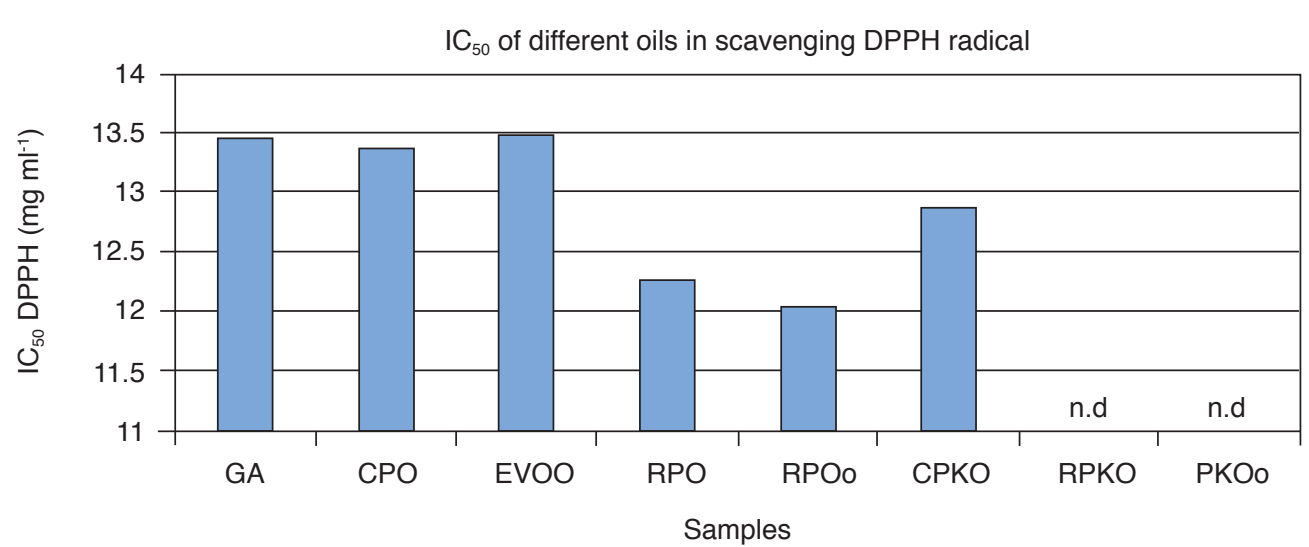

Note: n.d - not detected.

GA - gallic acid. DPPH - diphenyl -1 - picrylhdrazyl.

$\mathrm{CPO}$ - crude palm oil. RPO - refined palm oil.

RPOo - refine palm olein. CPKO - crude palm kernel oil.

RPKO - refine palm kernel oil. PKOo - palm kernel olein.

Figure 2. The $I C_{50}$ of different oil DPPH scavenging capacity of extra virgin olive oil (EVOO), palm and palm kernel oils extract.

Each value is expressed as the mean \pm standard error (S.E.) of triplicate analyses.

It is known that a number of natural extracts from selected fruits, herbs, spices and some vegetables are stable to autoxidation due to presence of natural phenolic compounds (Pokorny et al., 2001). From the previous analyses, it is proven that $\mathrm{CPO}$ contains the highest level of TPC compound compared to the other oils. The results of the present study reveal that there is a strong correlation between antioxidant activity and phenolic content. A lower concentration of phenolic compounds could lead to lower antioxidant capacities.

It is believed that the antioxidant properties of phenolics are a result of their ability to act as reducing agents, hydrogen donors and free radical quenchers and phenolics can also act as metal chelators which prevent the catalytic function of metal in the process of initiating radicals (Prior et al., 2005). Thus, phenolic compounds have an important role in antioxidant activities (Harborne, 1998). A good correlation between antioxidant activity and phenolic compounds was found in Bulgarian medicinal plants (Ivanova et al., 2005), Chinese medicinal plants (Zheng and Wang, 2001), some fruits, vegetables and grain products (Velioglu et al., 1998). The phenolic hydroxyl groups present in plant antioxidants have redox properties (Shahidi and Wanasundara, 1992; Pietta, 2000) allowing them to act as a reducing agent and a hydrogen donator.

The order of scavenging activity of the oil extracts obtained in this study was EVOO > $\mathrm{CPO}>\mathrm{CPKO}>\mathrm{RPO}>\mathrm{RPO}>\mathrm{RPKO}>\mathrm{PKO}$ (Figure 2). Almost all of the oil extracts showed that TPC was related to the scavenging activity (DPPH assay). Refined products of palm and palm kernel oils were less effective in quenching the DPPH radical than the crude extract at the same level. However, its effectiveness increased at higher concentrations. The activity was lower in the refined products of palm and palm kernel oils. Figure 2 suggested that during the refining process some antioxidant compounds are degraded or transformed. The reduction in antioxidant activity with refining processes were also reported for rapeseed oil, silkworm pupa oil and kenaf seed oil (Szydłowska-Czerniak et al., 2015; Liu et al., 2016; Chew et al., 2016).

The extract of crude palm and palm kernel oils showed high phenolic contents and correspondingly higher antioxidant activity. Concentration significantly affects the free radical scavenging activity for all samples. The results thus confirm that phenolic compounds rich vegetables possess strong antioxidant activity. A strong correlation has been observed between antioxidant activity and total phenolics (Cao et al., 1996; Wang et al., 1996; Prior et al., 1998).

\section{CONCLUSION}

This study quantified TPC expressed as mg $\mathrm{kg}^{-1}$ GAE in CPO, PKO and fractionated and refined products. The phenolics in the oils were successfully extracted using aqueous methanol. Recovery studies using oil spiked with gallic acid standards showed good recoveries ranging from $95.5 \%-99.5 \%$, indicating that the extraction method using aqueous methanol was efficient in extracting phenolics from palm oil. Quantification of phenolics extracted from CPO, RPO, PFAD using Folin-Ciocalteau assay found $\mathrm{CPO}$ to contain the highest level of TPC, while refining process has subsequently reduced the TPC in the oil. Based on the content of TPC in CPO, BPO, RPO and PFAD, a significant amount of the 
phenolics was probably lost through absorption of bleaching earth, volatilisation and degradation during the refining process. The amount of TPC is also dependent on and completely inseparable from the quality of the $\mathrm{CPO}$ as shown by samples collected from various regions. From this study, $\mathrm{CPO}$ was found to exhibit the highest antioxidant activity due to high content of TPC compared to other samples.

\section{REFERENCES}

ABUSHITA, A A; HEBSHI, E A; DAOOD, H G and BIACS, A P (1997). Determination of antioxidant vitamins in tomatoes. Food Chemistry, 60: 207-212. DOI: 10.1016/S0308-8146(96)00321-4.

ARUOMA, O I (1998). Free radicals oxidative stress and antioxidants in human health and disease. $J$. Amer. Oil Chem. Soc. Vol. 75: 199-212.

BALASUNDRAM, N; TAN, Y A; SAMBAN THAMURTHI, R and SUNDRAM, K (2005). Antioxidant properties of palm fruit extracts. Asia Pacific J. Clinical Nutrition, 4 (4): 319-324.

BLEKAS, G; PSOMIADOU, E; TSIMIDOU, $\mathrm{M}$ and BOSKOU, D (2002). On the importance of total polar phenols to monitor the stability of Greek virgin olive oil. European J. Lipid Science and Technology, 104 (6): 340346.

BOSKOU, D (1996). Olive Oil: Chemistry and Technology. AOCS Press, Champaign, IL, USA. p. 52-83.

BRAND-WILLIAMS, W; CUVELIER, $\mathrm{M}$ E and BERSET, C (1995). Use of a free radical method to evaluate antioxidant activity. Lebensm-Wiss Technology, 28: 25-30.

BRUNE, M; HALLBERG, L and SKANBERG, A B (1991). Determination of iron-binding phenolic groups in foods. J. Food Science, 56: 128-131.

CAO, G; SRFIE, E and PRIOR, R L (1996). Antioxidant capacity of tea and common vegetables. J. Agricultural and Food Chemistry, 44: 3425-3431.

CARRASCO-PANCORBO, A; CERRETANI, L; BENDINI, A; SEGURA-CARRETERO, A; GALLINATOSCHI, $\mathrm{T}$ and FERNANDEZ-GUTIERREZ, A (2005). Analytical determination of polyphenols in olive oil. J. Separation Science, 28: 837-858.

CHEW, S C; TAN, C P; LONG, K and NYAM, K L (2016). Effect of chemical refining on the quality of kenaf (hibiscus cannabinus) seed oil. Industrial Crops and Products, 89: 59-65.
DAI, J and MUMPER, R J (2010). Plant phenolics: Extraction, analysis and their antioxidant and anticancer properties. Molecules, 15: 7313-52.

DESHPANDE, S S and CHERVAN, M (1987). Determination of phenolic compounds of dry beans using vanillin, redox and precipitation assays. J. Food Science, 52: 332-334.

DE CLERCQ, N; DANTHINE, S; TUYET, N M; GIBON, V and DEWETTINCK, K (2012). Enzymatic interesterification of palm oil and fractions: Monitoring the degree of interesterification using different methods. J. Amer. Oil Chem. Soc. Vol. 89(2): 219-229. DOI: $10.1007 / \mathrm{s} 11746-011-1905-x$

DONOVAN, J L; MEYER, A S and WATERHOUSE, A L (1998). Phenolic composition and antioxidant activity of prunes and prune juice (Prunes domestica). J. Agricultural and Food Chemistry, 46: 1247-1252.

EARP, C F; AKINGBALA, J O; RING, S H and ROONEY, L W (1981). Evaluation of several methods to determine tannins in sorghum with varying kernel characteristics. Cereal Chemistry, 58: 234-238.

GIL, I M; TOMAS-BARBERAN, F A; HESS-PIERCE, B; HOLCROFT, M D and KADER, A A (2000). Antioxidant activity of pomegranate juice and its relationship with phenolic composition and processing. J. Agricultural and Food Chemistry, 48(10): 4581-4589.

GUTFINGER, T (1981). Polyphenols in olive oils. J. Amer. Oil Chem. Soc. Vol. 58: 996-968.

GRASSMANN, J; HIPPELI, $S$ and ELSTNER, E (2002). Plant's defense and its benefits for animals and medicine: Role of phenolics and terpenoids in avoiding oxygen stress. Plant Physiology Biochemistry, 40: $471-478$.

HAFIDI, A; PIOCH, D and AJANA, H (2005). Effects of a membrane-based soft purification process on olive oil quality. Food Chemistry, 92(4): 607-613. DOI: 10.1016/j.foodchem.2004.08.046.

HARBORNE, J B (1998). Phenolic compounds. Phytochemical Methods: A Guide to Modern Techniques of Plant Analysis (Harborne, J B ed.). Chapman \& Hall, London. p. 40-106.

HARBORNE, J B (1989). General procedures and measurement of total phenolics. Methods in Plant Phenolics (Dey, P M and Harborne, J B eds.). Academic Press, London. p. 2-9.

HERTOG, M G L; HOLLMAN, P C H and VENEMA, D P (1992a). Optimization of a quantitative HPLC 
determination of potentially anticarcinogenic flavonoids in vegetables and fruits. J. Agricultural and Food Chemistry, 40: 1591-1598.

HOFF, J E and SINGLETON, K I (1977). A method for determination of tannins in food by means of immobilized protein. J. Food Science, 42: 1566-1569.

IVANOVA, D; GEROVA, D; CHERVANKOV, $\mathrm{T}$ and YANKOVA, $\mathrm{T}$ (2005). Polyphenol and antioxidant capacity of Bulgarian medicinal plants. J. Ethnopharmacol, 96: 145-150.

KAUR, C and KAPOOR, H C (2001). Review: Antioxidants in fruits and vegetables - The millennium's health. International J. Food Science and Technology, 36: 703-725.

KIM, D O and LEE, C Y (2002). Current Protocols in Food Analytical Chemistry; Extraction and Isolation of Polyphenolics. John Wiley \& Sons, Inc., USA. p. I1.2.1-I1.2.12.

KOSKI, A; PEKKARINEN, S; HOPIA, A; WAHALA, K and HEINONEN, M (2003). Processing of rapeseed oil: Effects on sinapic acid derivative content and oxidation stability. European Food Research Technology, 217: 110-114.

KUSHAIRI, A; SOH KHEANG LOH; AZMAN, I; ELINA HISHAMUDDIN; MEILINA ONGABDULLAH; ZAINAL BIDIN MOHD NOOR IZUDDIN; RAZMAH, G; SHAMALA SUNDRAM and GHULAM KADIR AHMAD PARVEEZ (2018). Oil palm economic performance in Malaysia and R\&D progress in 2017. J. Oil Palm Res. Vol. 30(2): 163-195.

KUSHAIRI, A; SNGH, R and ONG-ABDULLAH, M (2017). The oil palm industry: Thriving with transformative technologies. J. Oil Palm Res. Vol. 29(4): 431-439.

KRYGIER, K; SOSULSKI, F and HOGGE, L (1982). Free, esterified and insoluble bound phenolic acids. 1. Extraction and purification procedure. J. Agricultural and Food Chemistry, 30: 330-334.

LEE, C Y and JAWORSKI, A W (1990). Identification of some phenolic compounds in white grapes. American J. Enology and Viticulture, 41: 87-89.

LIU, J; ZHENG, C; LIAO, S; SHI, Y; ZOU, Y; MU, L and LIN, G (2016). The effect of refining processes on antioxidant activity of silkworm pupa oil. J. Chinese Cereals and Oils Association, 31 (4): 51-56.

LIYANA-PATHIRANA, $\mathrm{C} \mathrm{M}$ and SHAHIDI, $\mathrm{F}$ (2006). Importance of insoluble-bound phenolics to antioxidant properties of wheat. J. Agricultural and Food Chemistry, 54: 1256-1264.

MARINOVA, E M and YANISHLIEVA, N VI (1997). Antioxidative activity of extracts from selected species of the family Lamiaceae in sunflower oil. Food Chemistry, 58: 245-248.

MATTHAUS, B and SPENER, F (2008). Introduction: What we know and what we should know about virgin oils - A general introduction. European J. Lipid Science and Technology, 110: 597-601. DOI: 10.1002/ ejlt.200800118.

MOURE, A;CRUZ, J M; FRANCO, D;DOMINGUEZ, J M; SINEIRO, J; DOMINGUEZ, H; NUNEZ, M J and PARAJO, J C (2001). Natural antioxidants from residual sources. Food Chemistry, 72: 145-171.

MUKHERJEE, S and MITRA, A (2009). Health effects of palm oil. J. Human Ecology, 26(3): 197-203. DOI: $10.1080 / 09709274.2009 .11906182$.

NEO, Y P; ARIFFIN, A; TAN, C P and TAN, Y A (2010). Phenolic acid analysis and antioxidant activity assessment of oil palm (E. guineensis) fruit extracts. Food Chemistry, 122: 353-359.

NERGIZ, C and UNAL, K (1991). Determination of phenolic acids in virgin olive oil. Food Chemistry, 39: 237-240.

OLESZEK, W; LEE, C Y; JAWORSKI, A W and PRICE, K R (1988). Identification of some phenolic compounds in apples. J. Agricultural and Food Chemistry, 36: 430-432.

PARK, Y K and LEE, C Y (1996). Identification of isorhamnetin 4'-glucoside in onions. J. Agricultural and Food Chemistry, 44: 34-36.

PAZMINO-DURAN, E A; GIUSTI, M M; WROLSTAD, $\mathrm{R}$ and GLORA, M B A (2001). Anthocyanins from banana bracts (Musa X paradisiacal) as potential food colorants. Food Chemistry, 73: 327-332.

PIETTA, P G (2000). Flavonoids as antioxidants. J. Nature Product, 63: 1035-1042.

POKORNY, J; YANISHLIEVE, N and GORDON, M (2001). Antioxidant in Food. Practical Applications. CRC Press, Boca Raton. p. 114-115.

PRIOR, R L; WU, X L and SCHAICH, K (2005). Standardized methods for the determination of antioxidant capacity and phenolics in food and dietary supplements. J. Agricultural and Food Chemistry, 53: 4290-302. 
PRIOR, R L; CAO, G; MARTIN, A; SOFIC, E; MCEWEN, J; O'BRIEN, C; LISCHNER, N; EHLENFELDT, M; KALT, W; KREWER, G and MAINLAND, M C (1998). Antioxidant capacity as influenced by total phenolics and anthocyanin content, maturity and variety of Vaccinium species. J. Agricultural and Food Chemistry, 46: 2686-2693.

RICE-EVANS, C A; MILLER, N T and PAGANGA, $G$ (1997). Antioxidant properties of phenolic compounds. Trends in Plant Science, 4: 304-309.

RICE, R D (1980). SCOPA Palm Oil Bleachability Test. $3^{\text {rd }}$ revision. Marfleet Refining Co. Ltd.

SAS INSTITUTE INC, (1997). SAS/STAT User's Guide. Version 6.12, SAS Institute Inc., Cary, NC.

SAMBANTHAMURTHI, R; SUNDRAM, K and TAN, Y A (2000). Chemistry and biochemistry of palm oil. Progress in Lipid Research, 39: 507-558.

SCRIMGEOUR, C (2005). Chemistry of fatty acids. Bailey's Industrial Oil and Fat Products. Sixth edition. John Wiley and Sons Incs. p. 1-43.

SHAHIDI, F and NACZK, M (1995). Food Phenolics: Sources, Chemistry, Effects and Applications. Technomic Publishing Company, Lancaster, PA.

SHAHIDI, F and WANASUNDARA, P K (1992). Phenolic antioxidants. Criti. Review and Food Science Nutrition, 32: 67-103.

SINGLETON, V L; ORTHOFER, R and LAMUELARAVENTOS, R M (1999). Analysis of total phenols and other oxidation substrates and antioxidants by means of Folin-Ciocalteau reagent. Method in Enzymology, 299: 152-178.

SZYDEOWSKA-CZERNIAK, A and ŁASZEWSKA, A (2015). Effect of refining process on antioxidant capacity, total phenolics and prooxidants contents in rapeseed oils. LWT - Food Science and Technology, 64 (2): 853-859. DOI: 10.1016 /j.lwt.2015.06.069.

SZYDEOWSKA-CZERNIAK, A; TROKOWSKI, K; KARLOVITS; G and SZŁYK, E (2011). Effect of refining processes on antioxidant capacity, total contents of phenolics and carotenoids in palm oils. Food Chemistry, 129(3): 1187-1192. DOI: 10.1016/j. foodchem.2011.05.101.

TAN, Y A and HOWE, W L (2005). Hydrophilic phenolics in palm. Paper presented at the Second International Congress on Antioxidant Methods. 2224 June 2005, Orlando, Florida, USA.

TEMPLE, N J (2000). Antioxidants and disease: More questions than answers. Nutrition Research, 20: 449-459.

TURA, D and ROBARDS, K (2002). Sample handling strategies for the determination of biophenols in food and plants. J. Chromatographic Science, 975: 71-93.

VAZQUEZ, R A C; JANERDEL, V and JANERDEL, V M I (1973). Grasas Aceites (Seville), 27: 185.

VELIOGLU, Y S; MAZZA, G; GAO, L and OOMAH, B D (1998). Antioxidant activity and total phenolics in selected fruits, vegetables, and grain products. J. Agricultural and Food Chemistry, 46: 4113-4117.

WANG, H; CAO, G H and PRIOR, R L (1996). Total antioxidant capacity of fruits. J. Agricultural and Food Chemistry, 44: 701-705.

WROLSTAD, R E W; TERRY, E A; HAEJUN, A; ERIC, A O; MICHAEL, H P; DAVID, S R; STEVENJ, S; CHARLES, F S and PETER, S (2002). Current Protocols in Food Analytical Chemistry. John Wiley \& Sons, Inc., USA. p. I1.1.1-I1.1.8 and I1.2.6-I1.2.1.

ZHENG, W and WANG, S Y (2001). Antioxidant activity and phenolic compounds in selected herbs. J. Agricultural and Food Chemistry, 49: 51655170 .

ZOU, Y; JIANG, Y; YANG, T; HU, P and XU, X (2012). 16-Minor Constituents of Palm Oil: Characterization, Processing and Application. AOCS Press. p. 471-526. DOI: 10.1016/B978-0-9818936-9-3.50019-8. 